\title{
European research priorities
}

SIR-The Advisory Subgroup on Human Reproduction of the European Medical Research Council (EMRC)* has published recommendations for research related to in vitro fertilization and embryo transfer' and has sought to identify priority areas in human reproduction research deemed particularly suitable for investigation by European scientists'.

The subgroup has noted the decrease of financial support for human reproduction research, particularly in the development of new and safe methods for fertility regulation, from both the public and private sectors. This contrasts strikingly with the recommendations for increased support for reproduction research by all sectors called for by 146 governments at the International Population conference in Mexico City in 1984, where particular emphasis was placed on the special needs of developing countries.

The subgroup believes that the scientific community has a particular contribution to make to research on new methods for fertility regulation for three reasons: its well-established record in this field, its long-standing tradition of providing medical and scientific assistance to developing countries and the close collaboration between its medical research councils and the European pharmaceutical industry.

In order to facilitate this collaboration. the subgroup held a consultation with representatives of interested European pharmaceutical companies in October 1985. At a meeting of the subgroup alone in April 1986, the following recommendations, which represent the views of the subgroup and do not necessarily reflect the views of the industry participants in the earlier consultation, were drawn up. (1) Steps should be taken, separately and jointly, by both industry and the medical research councils to increase the priority given to research on new methods of fertility regulation and on related fundamental research.

(2) The requirements for clinical trials of new contraceptive drugs and for the approval of such drugs for public use vary from country to country and are deemed unnecessarily complex in certain instances. The subgroup recommends that these requirements be modernized and standardized.

(3) A marked increase in the number and magnitude of liability lawsuits has caused some companies to withdraw from the fertility regulation field, and is one of the primary reasons for decreased work in this field. The subgroup recommends that European MRCs and industry representatives should work together to forestall this problem which threatens progress in this field.

(4) In view of the challenges confronting science to develop new methods of fertility regulation, the subgroup recommends consideration of the establishment of a European funding mechanism for reproduction research, sponsored and funded by industry and the MRCs and dedicated to the support of European research and research training adapted to the jointly derived requirements of both the private and public sectors.

E. Nieschlag

(Chairman of the EMRC Advisory Subgroup)

\section{MPG Clinical Research Unit}

for Reproductive Medicine,

Steinfurter Str. 107,

4400 Münster, FRG

*The advisory subgroup includes: E. Nieschlag (chairman), Max Planck Clinical Research Unit for Reproductive Medicine, University of Münster; B.M. Baccetti, Institute of Zoology. University of Siena: L. Cedard. Maternite Cochin. Paris; P. Corfman. Special Programme of Research, Develop ment and Research Training in Human Reproduction. World Health Organization, Geneva (observer); F. Haseltine. National Institute of Child Health and Human Development, National Institute of Child Health and Human Development
Bethesda (observer): E.D.B. Johansson. Pharmacia AB, Upp Bethesda (observer): E. D. B. Johansson. Pharmacia AB, Upp-
sala: D.W. Lincoln. MRC Reproductive Biology Unit. Edihurgh: C. Robyn, Hôpital Universitaire Saint Pierre, Brussel R. Vihko, Department of Clinical Chemistry, University of Oulu; G.H. Zeilmaker, Department of Endocrinology. Growth and Reproduction, Erasmus University. Rotterdam.

\section{Lancet, ii, 1187 (1983).}

lancet, i, $1228(1984)$

Atkinson. L.E.. Lincoln R., Forrest J.D. Family Planning perspectives, 17, 196 (1985)

4. Report of the International Conference on Population, United Nations Publication E/CONF. 76/19. New York (1984)

\section{Henderson Island}

SIR-In 1983 there was international concern when a strip-miner from West Virginia proposed to establish a settlement on Henderson Island in the Pitcairn group of the central South Pacific, as it was thought to be one of the few raised atolls still comparatively unaffected by human activity'. As much of the case for preserving the island depends upon its undisturbed state, we are now concerned to observe a statement in an influential journal that: "The recent discovery of several Polynesian occupational sites on Henderson ${ }^{2}$ shows that the island had, in fact, been inhabited in prehistoric times. On the basis of vertebrate remains from one of these sites we can now show that this period of human occupancy was accompanied by extinction and a consequent decrease in the species diversity of the island... The biota of Henderson Island can thus no longer be regarded as being in an unaltered state."

As this statement is liable to be quoted in support of further proposals for development of Henderson Island, it deserves some scrutiny.

The past Polynesian presence, which was already noted in our recent contribution on the birds of the island ${ }^{+}$, had so little impact that it is difficult to detect. Its only observed effects appear to have been the introduction of the Polynesian rat Rattus exulans, and perhaps some plants, and the possible extermination of some widespread but unobtrusive seabirds, whose survival may have been overlooked, and pigeons of the genus Ducula, attributed to two species because the wings were comparatively small whereas the jaw and legs were rather large.

The alternative possibility that instead of two additional species of pigeon occurring on one very small island alongside the small one which still survives, the pigeon bones may have belonged to a single large species showing the reduction in the wings common in insular birds, and also found in the flightless Henderson rail Porzana atra. which will be the next species at risk if the island is developed, is not discussed.

The list of petrels of the genus Pterodroma reported to survive in the group does not agree with our experience ${ }^{4}$, and it is rather surprising that all the bones should be identified as $P$. alba when it is doubtful whether this is distinguishable osteologically from one of the other species which is now commoner, $P$. arminjoniana.

It is to be hoped that this contribution will not be allowed to count against the case for preserving the island, which is apparently still at risk.

W.R.P. BOURNE

Department of Zoology,

The University, Aberdeen, UK

A.C.F. David

Oak End, West Monkton,

Taunton, Somerset, UK

Fosberg, F. R., Sachet. M.-H \& Stoddart D. R Atoll Res. Bull. 272, 1-47. (1983)

Sinoto. Y.S. J. Soc. Ocean. 39, 57-67(1983)

Steadman. D.W. \& Olson, S.L. Proc. natn. Acad. Sci U.S.A. 82, 6191-6195(1985)

4. Bourne, W.R.P. \& David, A.C.F. Notornis 30, 233-252 (1983)

\section{More bright ideas}

SIR-We read with interest of Greg Ojakangas's award-winning proposal to use a ROOPH (Readily Operative Overhead Protection by Hippos) in the event of nuclear attack (Nature 321, 373; 1986).

We wish to suggest the use of BOOBS (Blockade of Overhead Objects by Baby Seals) based on the same principle.

Canada could supply the animals (having an abundance of baby seals, especially in recent years) in return for protection. Use of an indigenous species has strategic and financial advantages, and, unlike hippos, baby seals are already cold-adapted for deployment at high altitudes or in winter (nuclear or otherwise).

MARK RAGAN Kathy SCHWARTZENTRUber 1141 Oxford Street,

Halifax,

Nova Scotia,

Canada B3H $3 Z 1$ 